\title{
The cardiovascular, metabolic and hormonal changes accompanying acute starvation in men and women
}

\author{
BY J. WEBBER AND I. A. MACDONALD \\ Department of Physiology and Pharmacology, University of Nottingham Medical School, \\ Clifton Boulevard, Nottingham NG7 $2 U H$
}

(Received 5 February 1993 - Revised 28 April 1993 - Accepted 10 May 1993)

\begin{abstract}
The effect of fasting for 12,36 and $72 \mathrm{~h}$ was studied in twenty-nine healthy subjects (seventeen women and twelve men). Measurements were made of cardiovascular variables, metabolic rate, respiratory exchange ratio, plasma metabolites, insulin, thyroid hormones and catecholamines. During starvation there were no significant changes in blood pressure, whilst heart rate (beats/min) increased at $36 \mathrm{~h}$ and remained elevated after 72 h (12 h 62.5 (SE 1.8), 36 h 68.0 (SE 1.9), 72 h 69.2 (SE 1.8); $P<0.001$ ). Forearm blood flow (FBF) increased progressively from 3.32 (SE 0.20) to 6.21 (SE 0.46) $\mathrm{ml} / 100 \mathrm{ml}$ per $\min (P<0.001)$. Resting metabolic rate $(\mathrm{kJ} / \mathrm{min})$ was significantly increased after $36 \mathrm{~h}$ of starvation (12 h 4.60 (SE 0.14 ), $36 \mathrm{~h} 4.88$ (SE 0.13 ), $P<0.001$ ), but was not significantly different from the $12 \mathrm{~h}$ value after $72 \mathrm{~h} \mathrm{(72} \mathrm{h} 4.72$ (SE 0.15$) P=0.06$ ). The respiratory exchange ratio fell progressively from 0.80 to 0.76 to $0.72(P<0.001)$. Blood glucose fell, whilst plasma glycerol and $\beta$-hydroxybutyrate rose and plasma lactate did not change. Plasma insulin and free triiodothyronine fell during starvation. Plasma adrenaline and noradrenaline were unchanged at $36 \mathrm{~h}$, but were significantly increased after $72 \mathrm{~h}$. Both sexes showed a similar pattern of response to starvation, although absolute values of blood pressure, forearm blood flow, metabolic rate and plasma catecholamines were higher in men than women. Acute starvation produces profound cardiovascular and metabolic changes which are not explained by the accompanying hormonal changes.
\end{abstract}

Starvation: Metabolic rate: Sex differences: Man

There is increasing evidence that the sympathetic nervous system (SNS) and catecholamines released from the adrenal medulla play a role in the control of energy expenditure in man. This regulatory function may be of major importance in the adaptations which occur during under- and overnutrition. It has long been known that prolonged undernutrition and fasting lead to a reduction in resting metabolic rate (RMR). This is due both to a decrease in body mass and to a fall in the energy expenditure of the remaining body tissue. The mediators of this latter process are uncertain but may include changes in thyroid hormone levels.

Demonstrating the role of the SNS in controlling energy expenditure in the resting state in healthy, normally-nourished individuals has been difficult. Some studies have shown a small reduction in RMR during $\beta$-blockade (Welle et al. 1991), whilst others have failed to show such an effect (Vernet et al. 1987). However, a clearer picture emerges when one examines stimulated thermogenesis. The SNS is activated following glucose ingestion (Berne et al. 1989) and $\beta$-blockade reduces the increment in metabolic rate seen in this situation (Astrup et al. 1989). Although RMR in the normally-fed state may not be much influenced by sympathoadrenal activity, manipulation of nutritional intake may cause more marked changes. Experimental work in rats has shown that fasting leads to suppression of SNS activity (as assessed by the turnover rate of tritiated noradrenaline in specific tissues; Landsberg \& Young, 1985), whilst refeeding reverses these changes. In man 
a similar pattern of changes in whole-body plasma noradrenaline turnover has been demonstrated during underfeeding and overfeeding (O'Dea et al. 1982).

The physiological changes accompanying short-term starvation in man have not been well characterized. During early starvation there is a profound natriuresis and only after a period of 3-5d does Na conservation occur (Boulter et al. 1973). Thus, unless salt supplementation is provided during this time-period, an obligatory diuresis and consequent volume depletion will occur. This will lead to compensatory cardiovascular reflexes and concomitant activation of the SNS, hence confounding any nutritionally-related (starvation) SNS changes. Where $\mathrm{Na}$ intake has remained constant, dieting and consequent weight loss in obese patients has been shown to reduce blood pressure as well as indices of SNS activity (Jung et al. 1979; Andersson et al. 1991). In normal-weight subjects the picture is less clear. Recent work has suggested there may be a paradoxical increase in RMR early in starvation (Mansell \& Macdonald, 1990) as well as increased limb blood flow. What factors mediate these changes are uncertain and in that study none of the hormonal changes seen could explain the observed alterations. In addition, recent studies have suggested there may be significant gender differences in the responses to metabolic stresses such as fasting (Clore et al. 1989) and hypoglycaemia (Amiel et al. 1993). The present study was designed, therefore, to examine the metabolic and physiological correlates of short periods of starvation in men and women, and to see whether changes in plasma catecholamines or other hormones could provide a satisfactory explanation of them.

\section{METHODS}

Twenty-nine healthy (twelve men), non-obese subjects (women: mean body mass index (weight $/$ height $^{2}$ ) 23.2 (SE 0.6 ) $\mathrm{kg} / \mathrm{m}^{2}$, mean age 21.7 (SE 0.7 ) years; men: mean body mass index $22.5(\mathrm{SE} 0.7) \mathrm{kg} / \mathrm{m}^{2}$, mean age 25.8 (SE 1.2) were recruited for the study. None was taking any medication other than the oral contraceptive pill. All gave written informed consent to the study which was approved by the University of Nottingham Medical School Ethical Committee.

The subjects were each studied on three occasions, after either a 12,36 , or $72 \mathrm{~h}$ fast, the $12 \mathrm{~h}$ (overnight) fast being taken as the postabsorptive control period against which the values at 36 and $72 \mathrm{~h}$ were compared. The studies were done in random order and there was a gap of at least $7 \mathrm{~d}$ normal food intake between each fasting period. All the women were studied during the follicular phase of the menstrual cycle. During the fasting period subjects were allowed water ad lib., proprietary flavoured carbonated drinks (One Cal; RHM Foods, Hartlepool) and black decaffeinated tea and coffee without sugar. Whilst fasting, subjects consumed $80 \mathrm{mmol} \mathrm{Na}$ and $50 \mathrm{mmol} \mathrm{K}$ daily as slow-release tablets to minimize the potentially confounding effects of fluid deprivation and intravascular volume depletion on SNS activity and cardiovascular reflexes.

Studies took place in a temperature-controlled room $\left(28^{\circ}\right)$ with the subjects wearing a Tshirt and shorts only. On arrival subjects rested supine whilst intravenous cannulas were inserted under local anaesthetic, and the monitoring equipment attached. For blood sampling a cannula was inserted retrogradely into a vein on the dorsum of the hand and kept patent with a slow-running infusion of saline $(154 \mathrm{mmol} \mathrm{NaCl} / 1)$. This hand rested in a warm-air box $\left(55-60^{\circ}\right)$ to obtain 'arterialized' venous blood samples (McGuire et al. 1976). Continuous recordings of $\mathrm{O}_{2}$ consumption and $\mathrm{CO}_{2}$ production were made using a ventilated-canopy indirect calorimeter (Fellows \& Macdonald, 1985). From the respiratory exchange data, calculations of metabolic rate (Weir, 1949) and respiratory exchange ratio (RER) were made. Heart rate (HR) was recorded from an electrocardiogram, and brachial arterial blood pressure was measured using an automated sphygmomanometer (Accutorr 
1A; Datascope Corporation, Paramus, NJ, USA). Right forearm blood flow (FBF) was determined by venous occlusion plethysmography using a mercury-in-rubber strain gauge (Whitney, 1953) with an arterial occlusion cuff at the wrist.

Indirect calorimetry was commenced after the subjects had been supine for at least $30 \mathrm{~min}$ and was continued for $1 \mathrm{~h}$. The mean values for the last $30 \mathrm{~min}$ were used in the calculation of RMR and RER. During the last 30 min measurements of FBF and blood pressure were taken. At the end of this period two samples of arterialized venous blood were withdrawn $10 \mathrm{~min}$ apart. Immediately after each blood sample had been taken arterialized glucose concentrations (YSI 23 AM; Yellow Springs Industries, Ohio 45387, USA) were measured. A portion of each arterialized blood sample was deproteinized in $0.1 \mathrm{M}-\mathrm{HClO}_{4}$, the supernatant fraction being stored at $-20^{\circ}$ for later analysis of lactate (coefficient of variation (CV) $7 \cdot 2 \%$ ), $\beta$-hydroxybutyrate $(\mathrm{CV} 5.6 \%$ ) and glycerol (CV $7.0 \%$ ) levels (Lloyd et al. 1978). The remainder of the arterialized blood sample was centrifuged at $4^{\circ}$ and the plasma separated. Plasma $(2 \mathrm{ml})$ was mixed with $75 \mu \mathrm{l}$ EGTA glutathione (antioxidant) and stored at $-80^{\circ}$ for subsequent determination of adrenaline and noradrenaline concentrations using HPLC with electrochemical detection (Macdonald \& Lake, 1985). Intra-assay CV were 6 and $4 \%$ for adrenaline and noradrenaline respectively; inter-assay values were 10 and $8 \%$ respectively. Plasma was stored at $-20^{\circ}$ for subsequent determination of free triiodothyronine (FT3; CV 6.0\%) and free thyroxine (FT4; CV 3.9\%; Amerlex M; Kodak Clinical Diagnostics Limited, Mandeville House, Amersham, Bucks.) and insulin levels (CV 11.7\%, mean control 7.1 mU/1; Coat-a-Count; DPL Division, Euro/DPC Limited, Abingdon Business Park, Abingdon, Oxon.).

Statistical analysis of the results was performed by one-way analysis of variance (ANOVA) to look at the changes over time for the group as a whole and for men and women separately, and by multivariate analysis of variance (MANOVA) to compare men and women and their responses. When significant differences were found with ANOVA paired $t$ tests were used to compare individual time points. The package Minitab (Minitab Inc., State College, PA, USA) was used for all statistical calculations.

\section{RESULTS}

There was a gap of at least 1 week of normal dietary intake between each period of starvation and in no subject were all three studies completed in a period less than 5 weeks. The studies were carried out using a randomized, balanced design, with no discernible order effect.

\section{Cardiovascular changes}

There was no significant change in systolic blood pressure (SBP) during the $72 \mathrm{~h}$ of starvation (Fig. 1). SBP was higher in men than women both basally $(111.8 v .103 .4 \mathrm{~mm} \mathrm{Hg}$, $P<0.001$ ) and at 36 and $72 \mathrm{~h}$ of starvation (sex effect $P<0.001$, MANOVA). There was no sex difference in the SBP response to starvation. Diastolic blood pressure (DBP) tended to fall progressively over this time-period (from 54.3 to 52.9 to $52.3 \mathrm{~mm} \mathrm{Hg}$ ) but this did not reach significance (time effect $P=0 \cdot 14$, ANOVA). DBP was higher in men than women (sex effect $P=0.002$, MANOVA), but the response to starvation was the same in both sexes.

HR increased during starvation from 62.5 to 68.0 to 69.2 beats $/ \mathrm{min}$ (time effect $P<$ 0.00 !, ANOVA). The HR at $36 \mathrm{~h}$ was significantly greater than that at $12 \mathrm{~h}(P=0.001)$, but there was no further significant increase at $72 \mathrm{~h}(P=0 \cdot 35)$. There was no sex difference in $\mathrm{HR}$, nor in the HR response to starvation.

FBF rose progressively from 3.32 to 4.87 to $6.21 \mathrm{ml} / 100 \mathrm{ml}$ per min (time effect $P<$ 0.001 , ANOVA). FBF at $36 \mathrm{~h}$ was greater than at $12 \mathrm{~h}(P<0.001)$ and that at $72 \mathrm{~h}$ was 

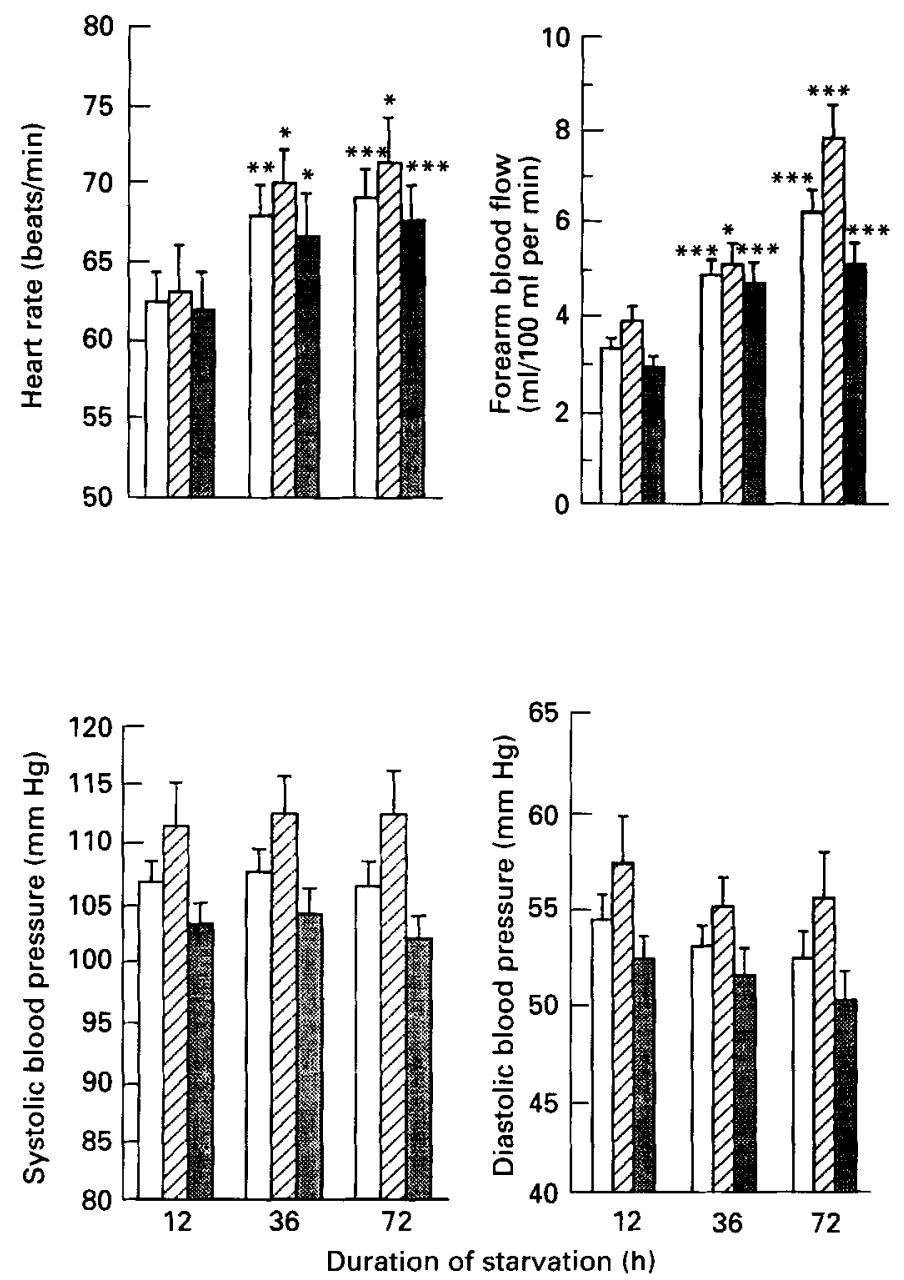

Fig. 1. Mean heart rate, forearm blood flow, systolic blood pressure and diastolic blood pressure for the group

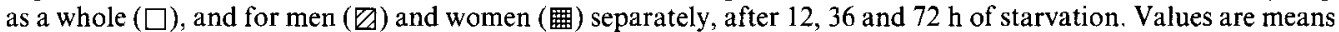
with their standard errors represented by vertical bars. Mean values for the 36 and $72 \mathrm{~h}$ periods were significantly different from that at $12 \mathrm{~h}$, for the group as a whole, and for men and women separately: ${ }^{*} P<0.05,{ }^{* *} P<0.01$, $* * * P<0.001$. For details of subjects and procedures, see pp. $438-439$.

greater than the $36 \mathrm{~h}$ value $(P=0.003)$. FBF was higher in men than women (sex effect $P<0.001$, MANOVA) and there was a greater increase in response to starvation in men (sex $\times$ time effect $P=0.03$, MANOVA).

\section{Metabolic changes}

For the group as a whole RMR rose from $4.60 \mathrm{~kJ} / \mathrm{min}$ at $12 \mathrm{~h}$ to $4.88 \mathrm{~kJ} / \mathrm{min}$ at $36 \mathrm{~h}$ and then fell again to a value of $4.72 \mathrm{~kJ} / \mathrm{min}$ at $72 \mathrm{~h}$ (Fig. 2 ; time effect $P<0.001$, ANOVA). The $36 \mathrm{~h}$ value was significantly greater than that at $12 \mathrm{~h}(P<0.001)$, but the $72 \mathrm{~h}$ value was not significantly different from the $12 \mathrm{~h}$ value $(P=0.06)$. At $72 \mathrm{~h}$ the RMR was less than that at $36 \mathrm{~h}(P=0.025)$. Absolute $\mathrm{RMR}(\mathrm{kJ} / \mathrm{min})$ was greater in men than women (sex effect $P<0.001$, MANOVA), but there was no sex difference in the fasting response. When men and women were analysed separately RMR did not change significantly in men over the 72 h period (time effect $P=0 \cdot 204$, ANOVA), but in women there was a significant 

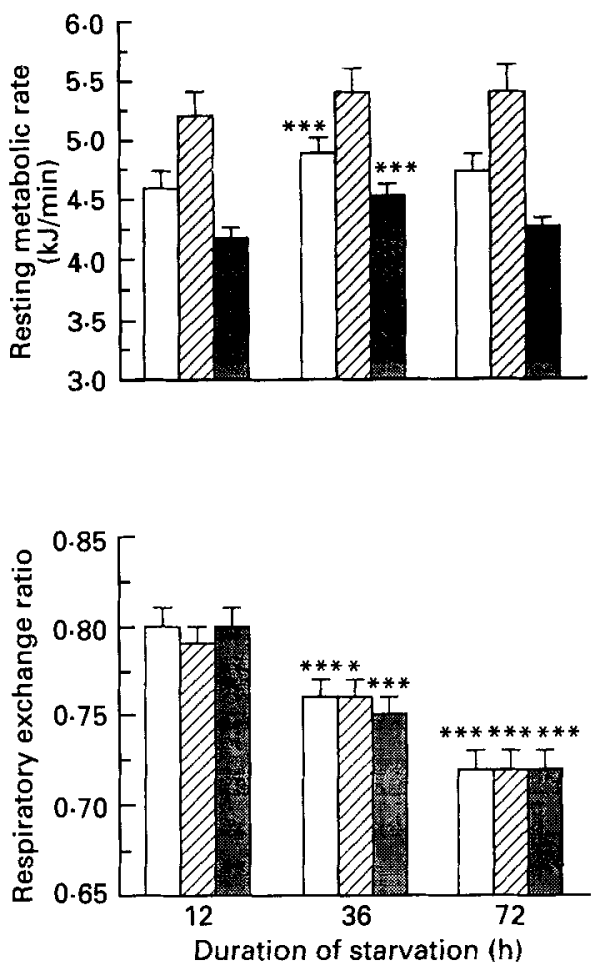

Fig. 2. Mean resting metabolic rate and respiratory exchange ratio for the group as a whole ( $\square$ ), and for men ( $\square$ )

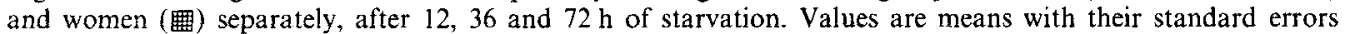
represented by vertical bars. Mean values for the 36 and $72 \mathrm{~h}$ periods were significantly different from that at $12 \mathrm{~h}$, for the group as a whole, and for men and women separately: ${ }^{*} P<0.05$, ${ }^{* * *} P<0.001$. For details of subjects and procedures, see pp. $438-439$.

change (time effect $P<0.001$, ANOVA). RER fell progressively (Fig. 2 ; time effect $P<$ 0.001 , ANOVA). There were no sex differences in RER, or its pattern of change during fasting.

Blood glucose fell from 4.48 to 3.81 to $3.10 \mathrm{mmol} / 1$ (Fig. 3 ; time effect $P<0.001$, ANOVA). There were no sex differences in blood glucose, or its pattern of change during starvation.

Blood glycerol rose during starvation (Fig. 3 ; time effect $P<0.001$, ANOVA). There was a significant difference between the 12 and $36 \mathrm{~h}$ values $(P<0.001)$, but not between the 36 and $72 \mathrm{~h}$ values $(P=0.72)$. Both sexes had similar values of glycerol at all time-points.

Blood lactate did not vary during starvation (Fig. 3). There were no sex differences in absolute values, or in response to starvation.

There was a progressive rise in $\beta$-hydroxybutyrate levels during starvation (Fig. 3 ; time effect $P<0.001$, ANOVA). No sex differences were demonstrated for $\beta$-hydroxybutyrate.

\section{Hormonal changes}

Plasma adrenaline levels increased during starvation (Fig. 4; time effect $P=0.015$, ANOVA). There was no significant difference between the $12 \mathrm{~h}$ and $36 \mathrm{~h}$ values $(P=0.068)$, but the $72 \mathrm{~h}$ value was greater than that at $12 \mathrm{~h}(P=0.006)$. Adrenaline was higher in men than in women (sex effect $P=0.017$, MANOVA). The change in adrenaline over starvation was not different in the two sexes. 

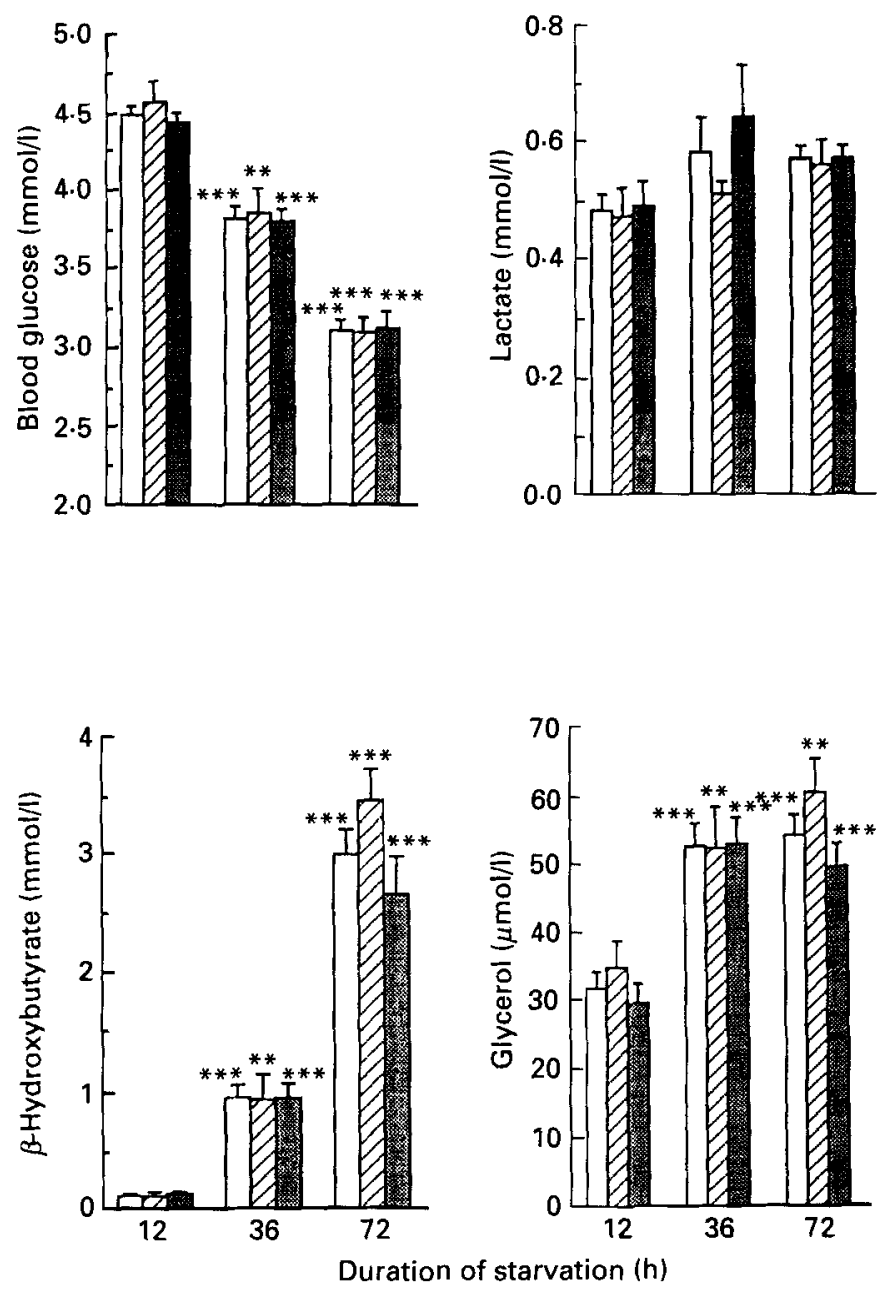

Fig. 3. Mean blood glucose, lactate, $\beta$-hydroxybutyrate and glycerol for the group as a whole ( $\square$ ), and for men ( represented by vertical bars. Mean values for the 36 and $72 \mathrm{~h}$ periods were significantly different from that at $12 \mathrm{~h}$, for the group as a whole, and for men and women separately: ${ }^{* *} P<0.01,{ }^{* * *} P<0.001$. For details of subjects and procedures, see pp. 438-439.

Plasma noradrenaline levels changed with starvation (Fig. 4; time effect $P<0.001$, ANOVA). There was no change in levels at $36 \mathrm{~h}$ compared with those at $12 \mathrm{~h}(P=0.89)$, but the levels at $72 \mathrm{~h}$ were significantly greater than those at both 12 and $36 \mathrm{~h}(P=0.002$ and $P<0.001$ respectively). Noradrenaline levels were higher in men than women (sex effect $P=0 \cdot 001$, MANOVA). The response to starvation was the same in men and women.

Plasma insulin fell progressively during starvation (Fig. 5; time effect $P<0.001$, ANOVA). There were no sex differences in absolute values or the response to starvation. FT3 levels gradually fell (Fig. 5; time effect $P<0.001$, ANOVA). FT3 levels were significantly higher in men compared with women (sex effect $P<0.001$, MANOVA). There was no sex difference in the response to starvation. FT4 levels did not change during starvation (Fig. 5). FT4 was higher in men than women (sex effect $P<0.001$, MANOVA). There was no sex difference over time. 

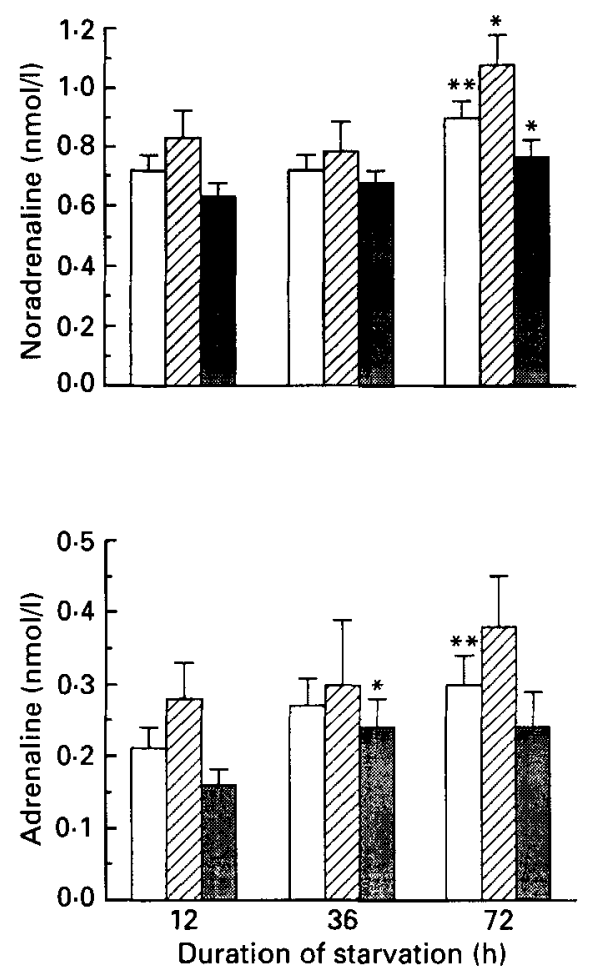

Fig. 4. Mean plasma noradrenaline and adrenaline for the group as a whole ( $\square$ ), and for men ( $\square$ ) and women

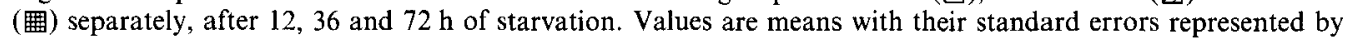
vertical bars. Mean values for the 36 and $72 \mathrm{~h}$ periods were significantly different from that at $12 \mathrm{~h}$, for the group as a whole, and for men and women separately: ${ }^{*} P<0.05,{ }^{* *} P<0.01$. For details of subjects and procedures, see pp. $438-439$.

FT3:FT4 fell with starvation from 0.40 to 0.35 to 0.27 at 12,36 and $72 \mathrm{~h}$ respectively (time effect $P<0.001$, ANOVA).

\section{DISCUSSION}

The present study confirms previous work concerning the cardiovascular, metabolic and hormonal changes accompanying acute starvation. In providing data on all these variables it also allows inferences to be made concerning the relationships between them. There was no significant change in SBP over the $72 \mathrm{~h}$ fast, but there was a tendency for DBP to fall. This dissociation between the effects of acute starvation on SBP and DBP has been noted previously in studies on healthy men (Bennett et al. 1984). The explanation is probably the marked limb vasodilatation that is seen in starvation rather than any effect due to volume depletion, this being prevented by concomitant salt supplementation. In the current study FBF rose progressively, almost doubling by $72 \mathrm{~h}$. Heart rate also increased significantly by $36 \mathrm{~h}$, but there was no further change by $72 \mathrm{~h}$.

An increasing number of studies have demonstrated the increase in RMR seen after 36 48 h of starvation (Mansell \& Macdonald, 1990; Mansell et al. 1990), in contrast to the decrease found after more prolonged starvation and undernutrition (Benedict, 1915). Our study confirms this observation and shows that the effect is a transient one which is mostly reversed by $72 \mathrm{~h}$. The likely cause of this elevation in RMR is the energy requirements of gluconeogenesis and ketogenesis, both of which are metabolically relatively expensive 

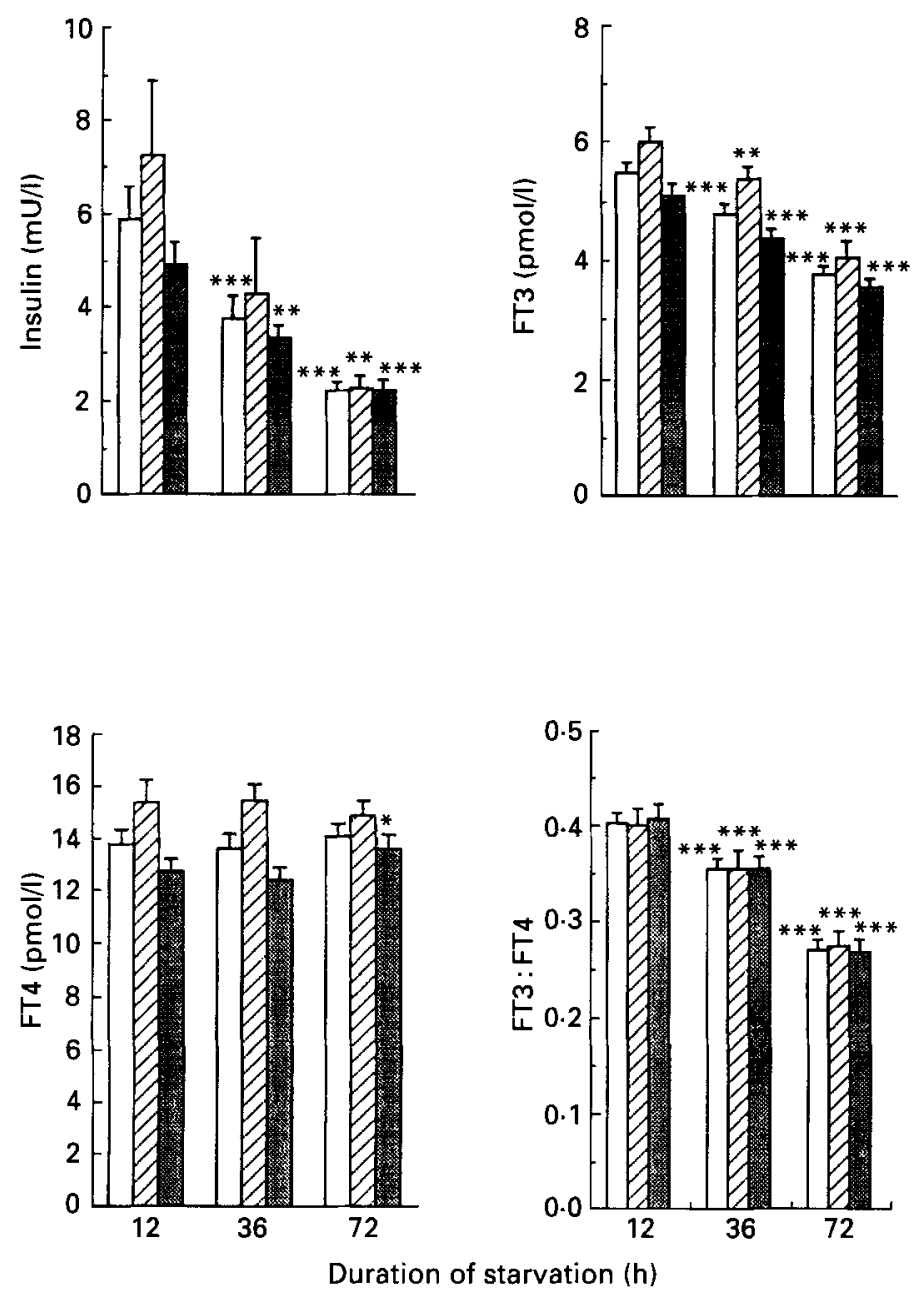

Fig. 5. Mean plasma insulin, triiodothyronine (FT3), free thyroxine (FT4) and FT3:FT4 for the group as a whole $(\square)$, and for men ( $\oslash$ ) and women (睡) separately, after 12,36 and $72 \mathrm{~h}$ of starvation. Values are means with their standard errors represented by vertical bars. Mean values for the 36 and $72 \mathrm{~h}$ periods were significantly different from that at $12 \mathrm{~h}$, for the group as a whole, and for men and women separately: ${ }^{*} P<0.05,{ }^{* *} P<0 \cdot 01$, *** $P<0.001$. For details of subjects and procedures, see pp. $438-439$.

processes. That our subjects were truly fasting is shown by the progressive fall in RER and in blood glucose, whilst $\beta$-hydroxybutyrate rose progressively. Blood glycerol rose reflecting increasing lipolysis at $36 \mathrm{~h}$ but there was no further change at $72 \mathrm{~h}$, perhaps because of the increasing utilization of glycerol as a gluconeogenic substrate and also due to feedback inhibition of lipolysis by the high blood ketone levels (Moller et al. 1990).

The continued fall in plasma insulin and FT3 levels whilst FT4 remained unchanged corroborates the findings of other workers (Palmblad et al. 1977; Beer et al. 1989). Although thyroid hormones are likely to have a role in the reduced metabolic rate of prolonged starvation, changes in their plasma levels cannot explain the elevated RMR of early starvation, nor the increase in resting HR seen in the present study.

Plasma adrenaline and noradrenaline were both significantly elevated after the $72 \mathrm{~h}$ fast relative to the overnight fasted levels. However, whereas adrenaline levels tended to rise 
Table 1. The relative changes in the cardiovascular system, thermogenesis and plasma hormones from 12 to $36 \mathrm{~h}$ and from 36 to $72 \mathrm{~h}$ of starvation*

\begin{tabular}{lcc}
\hline & $\begin{array}{c}\text { Changes from } \\
12 \text { to } 36 \mathrm{~h}\end{array}$ & $\begin{array}{c}\text { Changes from } \\
36 \text { to } 72 \mathrm{~h}\end{array}$ \\
\hline Heart rate & $\uparrow$ & $\leftrightarrow$ \\
SBP & $\uparrow$ & $\downarrow$ \\
DBP & $\leftrightarrow$ & $\downarrow$ \\
Forearm blood flow & $\uparrow$ & $\uparrow$ \\
Resting metabolic rate & $\uparrow$ & $\uparrow$ \\
Noradrenaline & $\leftrightarrow$ & $\uparrow$ \\
Insulin & $\leftrightarrow$ & $\downarrow$ \\
FT3 & $\downarrow$ & $\downarrow$ \\
FT4 & $\leftrightarrow$ & $\leftrightarrow$ \\
\hline
\end{tabular}

$\uparrow$, Increase; $\downarrow$, decrease ; $\leftrightarrow$, no change; SBP, systolic blood pressure; DBP, diastolic blood pressure; FT3, free triiodothyronine; FT4, free thyroxine.

* For details of subjects and procedures, see pp. 438-439.

progressively from 12 to 36 to $72 \mathrm{~h}$, plasma noradrenaline was unchanged at $36 \mathrm{~h}$. Thus, whereas RMR is most elevated after $36 \mathrm{~h}$, plasma noradrenaline, an indirect marker of SNS activity, is unchanged at this time. It would seem unlikely, therefore, that activation of the SNS is responsible for this rise in RMR. However, plasma catecholamine levels may not accurately represent sympathoadrenal activity. Plasma noradrenaline represents the spillover of the neurotransmitter from sympathetic post-ganglionic neurones, with the majority of noradrenaline being cleared by presynaptic re-uptake or by local metabolism (Esler et al. 1990). Thus, an increase in plasma levels may be due to increased production (enhanced SNS activity/increased rate of spillover) or decreased clearance. Other workers have assessed SNS activity by means of measuring muscle efferent sympathetic activity (MSA). Using this technique Andersson et al. (1988) showed that a $48 \mathrm{~h}$ fast in obese subjects caused an increase in both plasma noradrenaline (venous) and in MSA, although despite this apparent enhancement of SNS activity SBP and DBP fell dramatically. It should be noted here that the response of obese subjects to fasting may be quite different to normal-weight volunteers. In addition there may be changes in adrenergic sensitivity during starvation which may counteract or enhance any changes in SNS activity. Mansell et al. (1990) showed that the thermogenic and lipolytic responses to an adrenaline infusion were enhanced after a $48 \mathrm{~h}$ fast. However, there were no changes in the cardiovascular responses to adrenaline after the fast. Thus, there may be discrete activation of the SNS to different tissues such that there is not an all-or-nothing whole-body response.

The main sex differences noted in the present study were the elevated plasma levels of adrenaline, noradrenaline, FT3 and FT4 in men compared with women. That RMR was higher in men mainly reflects their larger size and greater fat-free mass. Although when analysed by MANOVA there was no sex difference in the changes in RMR during starvation, when the two groups were analysed separately there was no change in RMR in men after 36 and $72 \mathrm{~h}$, but in women RMR was increased at $36 \mathrm{~h}$ and then decreased after $72 \mathrm{~h}$ to a value not significantly different from that at $12 \mathrm{~h}$. No differences in the hormonal responses to starvation in the present study account for this disparity, but previous work has noted higher levels of glucagon in women than men (Merimee \& Fineberg, 1973), which may perhaps enhance rates of gluconeogenesis in women compared with men. However, in that study plasma glucose fell to lower values in women than in men after 36 and $72 \mathrm{~h}$ of 
fasting (so accounting for the greater rise in glucagon), whereas the present study did not show any difference in the pattern of fall of blood glucose. The explanation for this disparity is not clear, but may include different ages of the experimental subjects and differing degrees of physical fitness and activity during the study. The current study used arterialized venous blood, whilst Merimee \& Fineberg used venous plasma samples. In wellinsulinized subjects venous blood values may be lower than arterialized values, but in fasting subjects there is unlikely to be any significant difference between the two sampling sites. Moreover, values for whole-blood glucose are normally $10 \%$ lower than those for plasma glucose and, thus, lower values would be expected in the present study.

The only significant sex difference in the response to starvation was the greater FBF increment in men which may reflect a greater proportion of muscle compared with adipose tissue in the forearm of men. This argument implies that muscle blood flow increases more than that of adipose tissue during starvation, but data to confirm this are lacking. Only one study has examined adipose tissue blood flow in humans (four obese women) during acute starvation and there was a doubling of flow after a $4 \mathrm{~d}$ fast from 1.3 to $2.4 \mathrm{ml} / 100 \mathrm{ml}$ per min (Nielson et al. 1968). Basal blood flow, therefore, may be lower in subcutaneous adipose tissue than in skeletal muscle and, hence, any increase in blood flow to this tissue will have less overall effect on total limb blood flow than similar changes in the muscle component. In the current study total FBF doubled after a $72 \mathrm{~h}$ fast $(3 \cdot 32-6 \cdot 21 \mathrm{ml} / 100 \mathrm{ml}$ per min), but the separate contributions of muscle and adipose tissue were not assessed.

The overall pattern of changes is summarized in Table 1. This shows that whilst RMR is elevated at $36 \mathrm{~h}$, there is no change in catecholamines at this time-point and FT3 is actually reduced in comparison with $12 \mathrm{~h}$. Then, after $72 \mathrm{~h}$ of fasting RMR is not significantly different to the $12 \mathrm{~h}$ level, but noradrenaline (a marker of SNS activity) is increased. Likewise, the elevation in HR is mostly complete at $36 \mathrm{~h}$ and does not seem to be directly related to any of the hormonal changes observed. It is of note that the two variables which continued to rise progressively throughout the period of starvation were FBF and blood $\beta$-hydroxybutyrate levels. We have some data that infusion of $\beta$-hydroxybutyrate can raise FBF (J. Webber and I. A. Macdonald, unpublished results), although the mechanisms behind this are unclear. The transient elevation in RMR is probably mediated by enhanced rates of gluconeogenesis and ketogenesis, before the effect of these processes is overwhelmed by the profound changes in thyroid status which contribute to the slowing of cellular metabolism that predominates in more prolonged starvation.

In conclusion, the present study has shown that a $72 \mathrm{~h}$ fast in normal-weight subjects causes marked cardiovascular, metabolic and hormonal changes. However, the pattern of changes observed does not readily allow a hormonal explanation of the phenomena. In particular, sympathetic activity (as assessed by plasma catecholamine levels) does not correlate with elevations in RMR, HR or FBF. These data point to the need to measure other indices of sympathetic activity both of the whole body and of individual organs, as well as to look for other mediators of the adaptations which occur during starvation.

The authors are grateful to $\mathrm{Mr}$ S. Brown for measuring insulin, FT3 and FT4 concentrations, to Linda Ashworth for measuring intermediary metabolites, and to Ms J. Taylor and Mr D. Forster for catecholamine analyses. They are also grateful to all their subjects for giving of their time and giving up their food. The study was supported by a project grant from the Wellcome Trust.

Amiel, S. A., Maran, A., Powrie, J. K., Umpleby, A. M. \& Macdonald, I. A. (1993). Gender differences in counterregulation to hypoglycaemia. Diabetologia 36, 460-469. 
Andersson, B., Elam, M., Wallin, B. G., Bjorntorp, P. \& Andersson, O. K. (1991). Effect of energy-restricted diet on sympathetic muscle nerve activity in obese women. Hypertension 18, 783-789.

Andersson, B., Wallin, B. G., Hedner, T., Ahlberg, A. C. \& Andersson, O. K. (1988). Acute effects of short-term fasting on blood pressure, circulating noradrenaline and efferent sympathetic nerve activity. Acta Medica Scandinavica 223, 485-490.

Astrup, A., Simonsen, L., Bulow, J., Madsen, J. \& Christensen, N. J. (1989). Epinephrine mediates facultative carbohydrate-induced thermogenesis in human skeletal muscle. American Journal of Physiology 257, E340-E345.

Beer, S. F., Bircham, P. M. M., Bloom, S. R., Clark, P. M., Hales, C. N., Hughes, C. M., Jones, C. T., Marsh, D. R., Raggatt, P. R. \& Findlay, A. L. R. (1989). The effect of a 72-h fast on plasma levels of pituitary, adrenal, thyroid, pancreatic and gastrointestinal hormones in healthy men and women. Journal of Endocrinology 120 , $337-350$.

Benedict, F. G. (1915). A Study of Prolonged Fasting. Carnegie Institute Publication no. 203, Washington, DC: Carnegie Institute.

Bennett, T., Macdonald, I. A. \& Sainsbury, R. (1984). The influence of acute starvation on the cardiovascular responses to lower body subatmospheric pressure or to standing in man. Clinical Science 66, 141-146.

Berne, C., Fagius, J. \& Niklasson, F. (1989). Sympathetic response to oral carbohydrate administration. Evidence from microelectrode nerve recordings. Journal of Clinical Investigation 84, 1403-1409.

Boulter, P. R., Hoffman, R. S. \& Arky, R. A. (1973). Pattern of sodium excretion accompanying starvation. Metabolism 22, 675-683.

Clore, J. N., Glickman, P. S., Helm, S. T., Nestler, J. E. \& Blackard, W. G. (1989). Accelerated decline in hepatic glucose production during fasting in normal women compared with men. Metabolism 38, 1103-1107.

Esler, M., Jennings, G., Lambert, G., Meredith, I., Horne, M.\& Eisenhofer, G. (1990). Overflow of catecholamine neurotransmitters to the circulation: source, fate and functions. Physiological Reviews 70, 963-985.

Fellows, I. W. \& Macdonald, I. A. (1985). An automated method for the measurement of oxygen consumption and carbon dioxide excretion in man. Clinical Physics and Physiological Measurement 6, 349-355.

Jung, R. T., Shetty, P. S., Barrand, M., Callingham, B. A. \& James, W. P. T. (1979). Role of catecholamines in hypotensive response to dieting. British Medical Journal 1, 12-13.

Landsberg, L. \& Young, J. B. (1985). The influence of diet on the sympathetic nervous system. In Neuroendocrine Perspectives, vol. 4, pp. 191-218. [E. E. Muller, R. M. MacLeod and L. A. Frohman, editors]. Amsterdam: Elsevier Science Publishers.

Lloyd, B., Burrin, J., Smythe, P. \& Alberti, K. G. M. M. (1978). Enzymic fluorimetric continuous flow assays for blood glucose, lactate, pyruvate, alanine, glycerol and 3-hydroxybutyrate. Clinical Chemistry 24, $1724-1729$.

Macdonald, I. A. \& Lake, D. M. (1985). An improved technique for extracting catecholamines from body fluids. Journal of Neuroscience Methods 13, 239-248.

McGuire, E. A. H., Helderman, J. H., Tobin, J. D., Andres, R. \& Berman, M. (1976). Effects of arterial versus venous blood sampling on analysis of glucose kinetics in man. Journal of Applied Physiology 41, 565-573.

Mansell, P. I. \& Macdonald, I. A. (1990). The effect of starvation on insulin-induced glucose disposal and thermogenesis in humans. Metabolism 39, 502-510.

Mansell, P. I., Macdonald, I. A. \& Fellows, I. W. (1990). 48 hours starvation enhances the thermogenic response to infused epinephrine. American Journal of Physiology 258, R87-R93.

Merimee, T. J. \& Fineberg, S. E. (1973). Homeostasis during fasting. II. Hormone substrate differences between men and women. Journal of Clinical Endocrinology and Metabolism 37, 698-702.

Moller, N., Jorgensen, J. O. L., Moller, J. F., Bak, J. F., Porksen, N., Alberti, K. G. M. M. \& Schmitz, O. (1990). Substrate metabolism during modest hyperinsulinaemia in response to isolated hyperketonaemia in insulindependent diabetic subjects. Metabolism 39, 1309-1313.

Neilson, S. L., Bitsch, V., Larson, O. A., Lassen, N. A. \& Quaade, F. (1968). Blood flow through human adipose tissue during lipolysis. Scandinavian Journal of Clinical and Laboratory Medicine 22, 124-130.

O'Dea, K., Esler, M., Leonard, P., Stockigt, J. R. \& Nestel, P. (1982). Noradrenaline turnover during under- and over-eating in normal weight subjects. Metabolism 31, 896-899.

Palmblad, J., Levi, L., Burger, A., Melander, A., Westgren, U., von Schenck, H. \& Skude, G. (1977). Effects of total energy withdrawal (fasting) on the levels of growth hormone, thyrotropin, cortisol, adrenaline, noradrenaline, T4, T3, and rT3 in healthy males. Acta Medica Scandinavica 201, 15-22.

Vernet, O., Nacht, C.-A., Christin, L., Schutz, Y., Danforth, E. Jr \& Jéquier, E. (1987). $\beta$-adrenergic blockade and intravenous nutrient-induced thermogenesis in lean and obese women. American Journal of Physiology 253, E65-E71.

Weir, J. B. de V. (1949). New methods for calculating metabolic rate with specific reference to protein metabolism. Journal of Physiology 109, 1-9.

Welle, S., Schwartz, R. G. \& Statt, M. (1991). Reduced metabolic rate during $\beta$-adrenergic blockade in humans. Metabolism 40, 619-622.

Whitney, R. J. (1953). The measurement of volume changes in human limbs. Journal of Physiology 121, 1-27. 